\title{
Plasmacytoid dendritic cells in antiviral immunity and autoimmunity
}

\author{
TANG Fei ${ }^{1,2, \dagger}$, DU Qiumei ${ }^{1,2, \dagger}$, and LIU Yong-Jun ${ }^{3, *}$ \\ ${ }^{1}$ Center for Infection and Immunity, Institute of Biophysics, Chinese Academy of Sciences, Beijing \\ 100101, China \\ ${ }^{2}$ Graduate University of Chinese Academy of Sciences, Beijing 100049, China \\ ${ }^{3}$ Department of Immunology and Center for Cancer Immunology Research, University of Texas, \\ M.D. Anderson Cancer Center, Houston, Texas 77030, USA
}

\begin{abstract}
Plasmacytoid dendritic cells (pDCs) represent a unique and crucial immune cell population capable of producing large amounts of type I interferons (IFNs) in response to viral infection. The function of pDCs as the professional type I IFN-producing cells is linked to their selective expression of Toll-like receptor 7 (TLR7) and TLR9, which sense viral nucleic acids within the endosomal compartments. Type I IFNs produced by pDCs not only directly inhibit viral replication but also play an essential role in linking the innate and adaptive immune system. The aberrant activation of pDCs by self nucleic acids through TLR signaling and the ongoing production of type I IFNs do occur in some autoimmune diseases. Therefore, pDC may serve as an attractive target for therapeutic manipulations of the immune system to treat viral infectious diseases and autoimmune diseases.
\end{abstract}

\section{Keywords}

plasmacytoid dendritic cells; type I interferon; TLR7; TLR9; antiviral immunity; autoimmune diseases

Dendritic cells (DCs) are professional antigen-presenting cells within the immune system, crucial for the innate and adaptive immune responses to infections and for maintaining immune tolerance to self tissues [1]. Although they share many common features, multiple subtypes of DCs with distinct surface markers, migratory patterns, localization, life span and immune functions have been identified [2]. Plasmacytoid dendritic cells (pDCs), an important type of dendritic cells, were identified as the major type I interferons (IFNs) producing cells in response to viral infection about 10 years ago by our laboratory $[3,4]$ and now much progress has been made towards the better understanding of pDC biology.

Increasing evidence has demonstrated that the dysregulated pDC activation and excessive expression of IFN-a from pDCs are associated with autoimmune diseases [5-8], which draws more and more attention from immunologists. After more than two decades of effort by researchers, pDCs finally claim their place in the hematopoietic chart as an important cell type in antiviral immunity and autoimmunity. In this review, we summarize the remarkable

\footnotetext{
(C) Science China Press and Springer-Verlag Berlin Heidelberg 2010

*Corresponding author: yjliu@ mdanderson.org.

†Contributed equally to this work
} 
progress made over the past 10 years in understanding pDC biology, with focus on the molecular mechanisms for pDCs in antiviral immunity and autoimmunity.

\title{
1 Identification of pDCs as the Type I interferon-producing cells
}

\author{
In the 1950s, pathologists Lennert and Remmele [9] described a cell type with plasma cell \\ morphology located in the $\mathrm{T}$ cell area of human lymphoid tissues. It was renamed \\ "plasmacytoid T cells" due to the expression of T-cell marker CD4 [10,11]. Later, Facchetti \\ et al [12] found that plasmacytoid T cells expressed several myelomonocytic makers but \\ lacked B or T lymphocyte associated antigens and suggested to use the item "plasmacytoid \\ monocytes". In 1997, Grouard et al.[13] from our laboratory isolated plasmacytoid T cells \\ from human tonsils for the first time and demonstrated that these cells differentiated into \\ dendritic cells with IL-3 or IL-3 plus CD40 ligand (CD40L). Therefore, "plasmacytoid \\ dendritic cell precursors" were then used to describe this specific cell type, now called \\ "plasmacytoid DCs" (pDCs).
}

In the 1970s, it was clear that human peripheral blood leukocytes contain a cell type that produce more type I IFNs than other cell types after exposure to viruses [14]. Extensive studies concluded that these type I interferon-producing cells (IPC) were not B cells, T cells, NK cells, monocytes, or macrophages [15-17]. In 1999, our laboratory formally demonstrated that pDCs are actually IPCs, which have the capacity to produce 100-1000 times more type I IFNs than other blood leukocytes following virus infection [3]. Later, pDCs were identified in other species including mice, rats, pigs, sheep and non-human primates [4].

\section{Characterization of plasmacytoid dendritic cells}

\subsection{The morphology of pDCs}

Human pDCs represent $0.2 \%-0.8 \%$ of peripheral blood mononuclear cells (PBMCs) and display plasma cell morphology on Giemsa staining. They are slightly smaller than CD14 ${ }^{+}$ monocytes, but bigger than resting lymphocytes (Figure 1A). Whereas a monocyte displays a horseshoe-shaped nucleus (Figure 1B), a pDC displays an eccentric kidney-shaped nucleus (Figure 1A). Whereas monocytes have many vesicles in the cytoplasm, pDCs have a basophilic cytoplasm that contains a pale Golgi zone. By transmission EM, pDCs display nuclei with marginal heterochromatin and cytoplasm containing well-developed rough endoplasmic reticulum, small Golgi apparatus, and many mitochondria (Figure 1D). By scanning EM, pDCs display a smooth, round, lymphoid morphology and are 8-10 $\mu \mathrm{m}$ in diameter (Figure 1E). In particular, whereas the $\mathrm{CD} 11 \mathrm{c}^{+}$blood immature myeloid DCs (mDCs) display dendrites (Figure 1C), immature pDCs display no dendrites. Immature pDCs died rapidly in culture, but in the presence of IL-3 and CD40L they differentiated into cells with mature interdigitating DC morphology [13] (Figure 1F).

\subsection{Surface phenotype of human pDCs}

Human pDCs are $\mathrm{CD} 4^{+} \mathrm{CD} 45 \mathrm{RA}^{+} \mathrm{HLA}-\mathrm{DR}{ }^{+} \mathrm{CD} 123^{\text {high }} \mathrm{ILT}^{+}{ }^{+} \mathrm{ILT} 1^{-} \mathrm{CD} 11 \mathrm{c}^{-}$lineage ${ }^{-}$cells. They do not express the lineage-specific markers for all the known cell types within the immune system, including surface and cytoplasmic immunoglobulin and CD19 (B cells), TCR and CD3 complexes (T cells), CD14 (monocytes), CD16 and CD56 (NK cells), and CD11c (myeloid DCs). Although pDCs were named plasmacytoid monocytes because of their expression of MHC class II and myeloid antigen such as CD68, pDCs do not express most of the antigens expressed on myeloid cells, such as CD11b, CD13, CD14, or CD33. They also do not express nonspecific esterase, and they lack phagocytic activity. These facts together suggest that $\mathrm{pDCs}$ belong to an independent cell lineage within the immune system. Two additional markers, BDCA-2 (CD303) and BDCA-4 (CD304), are restricted to human 
pDCs in peripheral blood and bone marrow [18]. In order to get pDCs of higher than 99\% purity from human peripheral blood, isolation of $\mathrm{CD}^{+} \mathrm{CD}^{+} 1 \mathrm{c}^{-} \mathrm{Lin}^{-}(\mathrm{CD} 3, \mathrm{CD} 14, \mathrm{CD} 16$, CD19, CD56) cells by three-color immunofluorescence cell sorting would be a preferable method [4].

\subsection{Development, localization and migration of pDCs}

The origin of plasmacytoid dendritic cells has been controversial because both common lymphoid progenitors (CLP) and common myeloid progenitors (CMP) give rise to pDCs $[19,20]$. It appears that pDCs represent a unique hematopoietic lineage, whose development is much more flexible than both conventional lymphoid (B, T, NK) and myeloid (monocytes and granulocytes) cells [21]. Human pDCs are identified in bone marrow and some primary lymphoid tissues such as fetal liver and thymus, which suggests that pDCs develop from hematopoietic stem cells (HSCs) [22]. FLT3 ligand is the only known cytokine that is most critical for pDC development from HSCs in humans and mice [22-25]. The development of human pDCs is regulated by various transcription factors, such as the ETS family protein Spi-B [26] and E-box protein E2-2 [27,28]. During adult life, pDCs appear to be produced constantly from bone marrow. Granulocytes colony-stimulating factor (G-CSF), another important cytokine in $\mathrm{pDC}$ development, may promote $\mathrm{pDC}$ immobilization from bone marrow [29,30]. After leaving the bone marrow, pDCs appear to migrate into the T cell-rich areas of the secondary lymphoid tissues through high endothelial venule (HEV) in lymph nodes and mucosa-associated lymphoid tissues, as well as through marginal zones of the spleen under steady-state conditions [31,32]. Kinetic studies indicate that pDCs in mice have an average life span of about 2 weeks [33].

\section{Function of plasmacytoid dendritic cells in anti-viral immunity}

\section{1 pDCs are professional Type I IFN-producing cells in antiviral infections}

Upon virus infection, pDCs produce large amounts of type I IFNs within $24 \mathrm{~h}$ while other blood cell types produce only small or undetectable amounts [3]. When stimulated by viruses, pDCs dedicate approximately $60 \%$ of their new transcriptional activity to make type I IFNs, including all transcripts of 19 different type I IFN subtypes tested [34]. After the first $24 \mathrm{~h}$ of virus stimulation, pDCs produce only a fraction of type I IFNs and do not make a secondary response when stimulated further with the same virus or different viruses [34]. pDCs also produce moderate amounts of IL- 6 and TNF- $\alpha$ as B cells and mDCs, but small amounts of IL-12, and no IL-10 [34]. In vivo depletion of mouse $\mathrm{pDCs}\left(\mathrm{Ly} 6 \mathrm{G}^{+} / \mathrm{C}^{+}\right.$cells) by anti-Ly6G/C treatment abrogated the IFN-a production in response to cytomegalovirus infection [35-37]. All these data indicated that pDCs are professional type I IFNs-producing cells in anti-viral innate immune responses. The rapid production of type I IFNs by pDCs is independent of the positive feed-back effect of IFN- $\beta$, as pDCs in type I IFN receptordeficient mice produced similar amounts of IFN- $\alpha$ as wild type mice in response to viruses [37].

\section{2 pDCs sense viral nucleic acids through TLR7 and TLR9}

Toll-like receptors (TLRs) are a family of membrane molecules recognizing pathogenassociated molecular patterns (PAMPs), highly conserved from Drosophila to human [3840]. CD11 $\mathrm{c}^{+} \mathrm{mDC}$ express TLR1, TLR2, TLR3, low levels of TLR5, TLR6, TLR8, and TLR10, while monocytes express TLR1, TLR2, TLR4, TLR5, TLR8, and a low level of TLR6 [41]. In marked contrast to mDCs and monocytes, pDCs preferentially express high levels of TLR7 and TLR9 [41,42] (Figure 2). TLR7 is identified as a receptor for pDCs to recognize single-stranded RNA (ssRNA) to detect infection by ssRNA viruses [43-45]. The pDCs isolated from the bone marrow of TLR7-deficient mice secreted significantly reduced levels of IFN-a in response to VSV vesicular stomatitis virus (VSV) infection, thus 
indicating the requirement of TLR7 in IFN-a production by pDCs [45]. The recognition of viral double-stranded DNA (dsDNA) by pDCs is mediated by TLR9, as the pDCs lacking TLR9 are incapable of secreting IFN- $a$ in response to dsDNA viruses [46-48].

The signaling pathway of TLR7 and TLR9 involves a multi-protein signal-transducing complexes, including myeloid differentiation primary-response gene 88 (MyD88), tumornecrosis factor receptor-associated factor 6 (TRAF6) [49-51], interleukin 1-receptorassociated kinase (IRAK1/IRAK4) [52-54], and Bruton's tyrosine kinase (BTK) [55] (Figure 2). TLRs bind to MyD88 through death-domains interaction, further recruit and associate with TRAF6, BTK and IRAK1/IRAK4 in the cytoplasm, leading to the activation of interferon-regulatory factor 7 (IRF7), nuclear factor- $\mathrm{kB}$ (NF- $\mathrm{kB}$ ), and mitogen-activated protein kinases (MAPKs). pDCs constitutively express a high level of IRF7 [56-58], partially contributing to the rapid production of robust type I IFNs in response to viruses. Other IRFs were also reported to be expressed by pDCs [34] and participate in type I IFNs production, such as IRF4 [59], IRF5 [60,61], and IRF8 [62]. As TLR7 and TLR9 translocate from the endoplasmic reticulum to the endosomal compartment upon stimulation, additional cellular factors were reported to be involved in TLR-mediated activation of pDCs, such as UNC93B [63], ER chaperone gp96 [64].

\section{3 pDCs link innate and adaptive immunity}

Besides the direct antiviral effect, type I IFNs produced by pDCs also promote the antiviral functions of mDCs, NK cells, T cells, and B cells, thus linking the innate with adaptive immunity in anti-viral responses. In vitro IFN-a enhanced the maturation of mDCs, and led to their production of IL-12 [65]. In HIV infection, pDCs induced a bystander maturation of $\mathrm{mDCs}$ dependent on the production of type I IFNs and TNF- $\alpha$ [66]. pDCs act sequentially on CD40-activated B cells, with IFN- $\alpha / \beta$ generating non-Immunoglobulin (Ig)-secreting plasma blasts and IL-6 inducing their differentiation into Ig-secreting plasma cells [67]. In the 1980s, NK cell activation and cytotoxicity were reported to be dependent on HLA-DR ${ }^{+}$ cells (now known as pDCs) in PBMCs $[68,69]$. Using highly purified pDCs and NK cells, the direct activation of NK cells by pDCs was demonstrated. Hanabuchi et al. [70] reported that GITRL plays an important role for $\mathrm{CpG}$ oligodeoxyribonucleotide (CpG-ODN) activated pDCs to promote NK cytotoxicity. Type I IFNs could induce cross-presentation during virus infection, and promote the proliferation of antigen-specific $\mathrm{CD} 8^{+} \mathrm{T}$ cells, and the commitment of naive T cells into Th1 cells through the signal transducer and activator of transcription 1 (stat1), stat 3 activation and T-bet expression [71-73]. After being activated by viruses or IL-3 plus CD40L, pDCs differentiated into mature DCs, inducing polarization of naïve $\mathrm{CD} 4^{+} \mathrm{T}$ cells into Th1 and Th2 cells $[74,75]$. In addition, $\mathrm{pDC}$ have the intrinsic ability to induce IL-10 production by T cells, which is dependent on the expression of inducible costimulator ligand (ICOSL) [76].

\section{4 pDCs and human viral infectious diseases}

As the major type I IFN-producing cells in the innate immune system, pDCs respond to a wide range of viruses, including human immunodeficiency virus type I (HIV-1), influenza virus, Sendai virus, herpes simplex virus (HSV), etc.

In HIV infection, pDCs express CD4, CCR5, and CXCR4, which serve as the co-receptors for entrance of HIV $[13,77]$. It has been reported that in HIV-infected patients, the function of circulating pDCs in the blood was impaired [78-81]. There was a negative correlation between the pDCs number in the blood and the viral load, implying the significance of pDCs in HIV infection [80]. It was also reported that HIV-1 could turn pDCs into TNF-Related Apoptosis-Inducing Ligand (TRAIL) expressing killer cells, and down-regulate the coreceptors for HIV entry [82]. However, it becomes controversial about the role of pDCs in 
AIDS pathogenesis based on the recent investigations [83-85]. Mandle et al. found that pDCs produce much less amounts of IFN-a in SIV natural host Sooty mangabeys (SMs), in which the virus is nonpathogenic, compared with the pDCs from the pathogenic virus host Rhesus macaques (RMs). Global genomic analysis of host gene expression in SIV-infected SMs and RMs revealed that SIV infection triggered strong IFN-a production in both species, with this immune-activation only efficiently restricted in SMs $[84,85]$. The distinction probably correlates with the different disease progression between these two species $[83,86,87]$. This reminds us that suppression of the sustained immune activation may be the key to control the disease progression in HIV-infected patients, and pDC would serve as a target in this process.

In hepatitis B virus (HBV) infected patients, the decreased frequency and impaired function of pDCs to produce the type I IFNs were reported, which may be associated with HBV persistence [88-90]. Clinically, chronically HBV-infected pediatric patients favorably responding to IFN- $a$ therapy are characterized by prominent pDCs recovery [91]. One possible explanation for the decreased pDCs frequency may be the infection of pDCs by HBV. By PCR analysis of covalently closed circular DNA (cccDNA) and electron microscopy of circulating pDCs from high viremic HBV carriers, no infection of pDCs by $\mathrm{HBV}$ was detected [92]. Still it is possible that $\mathrm{pDCs}$ could take up HBV and lead to the functional impairment. However, whether HBV could affect the cytokines production of pDCs in response to TLR ligands, thus leading to the impairment of the pDCs function and the molecular mechanism underlying these phenomena need to be addressed.

Avian influenza virus $\mathrm{H} 5 \mathrm{~N} 1$ has caused great concern worldwide due to the high mortality rate of $>50 \%$ in infected humans since the first documented cases occurred in Hong Kong in 1997. Viral RNA and viable viruses were detected in blood and available histopathological specimens of deceased patients [93,94], implying the viral evasion of host immunity. Unlike mDCs, which could be infected by influenza H5N1, pDCs are resistant to infection and secret higher amounts of IFN-a compared with low pathogenicity influenza viruses (H1N1 or H3N2) $[95,96]$. Treatment of DCs with IFN-a $(10000 \mathrm{U} / \mathrm{mL})$ completely abolished H5N1-induced killing and significantly reduced viral RNA.

Soon after the first case of swine-origin H1N1 virus infection was reported in Mexico, H1N1 caused a worldwide pandemic. Little is known about the pathogenesis and immune responses to H1N1 infection. Although a newly released paper described the type I IFNs production in monocyte-derived DCs and macrophages, the capability of pDCs to produce type I IFNs in response to H1N1 still needs to be investigated [97].

\section{Function of plasmacytoid dendritic cells in autoimmunity}

\subsection{Mechanisms for innate tolerance to self-DNA and self-RNA}

It is very critical for the immune system to avoid the recognition of self-DNA and self-RNA while retaining the ability to sense microbial nucleic acids. The innate immune system appears to have elaborated several distinct mechanisms to discriminate pathogen-derived exogenous nucleic acids and host-derived self nucleic acids.

First, the subcellular localization of TLR7 and TLR9 to endosomal vesicles, rather than to the cell surface, is likely a crucial mechanism for restricting the immune response to nucleic acids from pathogens that invade the cells by endocytosis, whereas self DNA and self-RNA fail to spontaneously access these compartments [98]. Second, the abundant DNases and RNases in the extracellular environment ensure a rapid degradation of self nucleic acids released from dying cells and damaged cells but not the nucleic acids in viruses or microorganisms. Third, during infection viral and bacterial genomes are taken up into 
endosome where they could readily reach the concentrations required for TLRs activation, while both extracellular and intracellular self nucleic acids are normally not efficiently concentrated in endosome without additional components to facilitate the process of uptake [99]. Finally, viral or bacterial DNA contains multiple unmethylated $\mathrm{CpG}$ motifs that bind and activate TLR9, whereas mammalian self-DNA contains fewer such motifs and these are mostly masked by methylation [100]. Moreover, vertebrate-specific RNA modification, including poly(A) tails and nucleotide methylation, also contributes to the low immunogenicity of self RNA [101].

\subsection{Recognition of self-DNA/RNA by pDCs causes autoimmune pathology}

There is considerable emerging evidence that TLRs recognition of self nucleic acids occurs under certain circumstances although the innate immune system evolves distinct mechanisms to prevent self recognition. The chronically activated pDCs and the IFN- $a$ that they produce in response to self nucleic acids are contributing factors in the pathogenesis of some autoimmune diseases, such as systemic lupus erythematosus (SLE) and psoriasis.

In patients with SLE, pDCs are continuously activated by circulating immune complexes (ICs) comprising self DNA or RNA and antibodies to self DNA/chromatin or small nuclear ribonucleoprotein (snRNP) [102,103] (Figure 3). Multiple studies have indicated that the increased serum levels of IFN-a observed in many SLE patients correlate with both disease activity and key disease markers, such as anti-DNA antibodies [104,105]. DNA-containing ICs isolated from the sera of patients with SLE trigger type I IFNs production by pDCs through the binding of DNA-specific autoantibodies to low-affinity Fc receptor for IgG (FcrRIIA). HMGB1 (high-mobility group box 1 protein), a nuclear DNA-binding protein released from necrotic cells, has the ability to enhance type I IFNs production by pDCs through a TLR9-MyD88 pathway involving the multivalent receptor RAGE (receptor for advanced glycation end-products) [106]. The resulting production of high levels of IFN-a by $\mathrm{pDCs}$ induces an unabated activation and maturation of $\mathrm{mDCs}$ that stimulate autoreactive T cells [107]. Furthermore, pDCs-derived type I IFNs, together with IL-6, stimulate the differentiation of autoreactive B cells into autoantibody-secreting plasma cells [67] and the expression of B cell survival factors such as BAFF (B cell-activating factor of the TNF family) $[108,109]$. This potentially leads to a positive feedback loop (Figure 3 ) in which antibodies produced by autoreactive B cells activate IFN- $a$ from $\mathrm{pDCs}$, which in turn promote B cells survival, activation and differentiation [110].

The aberrant activation of pDCs by self-DNA and self RNA also triggers autoimmunity in psoriasis (Figure 3). Psoriasis is one of the most common human skin diseases and is characterized by excessive growth and aberrant differentiation of keratinocytes [111]. Normally pDCs are not present in healthy skin but infiltrate the skin of psoriasis patients and pDCs-derived type I IFNs were demonstrated to trigger the local activation of myeloid dentritic cells and autoreactive T cells, leading to the development of psoriasis [112]. In psoriasis skin, pDCs are activated to produce type I IFNs by abnormally sensing extracellular self-DNA coupled with an antimicrobial peptide called LL37 [113]. LL37 secreted by keratinocytes and neutrophils binds self DNA fragments from dying cells through its cationic and $a$-helical properties, forming large aggregated and condensed structures that are resistant to extracellular nuclease degradation. The LL37-DNA complexes then translocate into the endocytic compartment of $\mathrm{pDCs}$, a process which involves the attachment of LL37 to proteoglycans in the cell membrane followed by lipid-raft-mediated endocytosis [114]. The aggregated self-DNA-LL37 complexes are retained in early endosomes of pDCs to trigger a sustained IFNs induction via TLR9/MyD88/IRF7 signaling (Figure 3). A recent report reveals that self-RNA-LL37 complexes are also present in psoriatic skin lesions, triggering pDCs to secret abundant IFN-a [115]. 
The high level of type I IFNs caused by recognition of self-DNA and self-RNA by pDCs could be a more general and underappreciated factor in driving autoimmune diseases. The elevated percentage of $\mathrm{pDCs}$ has been found in the synovial fluids of patients with rheumatoid arthritis (RA) and psoriatic arthritis (PA), which indicates that chemokine-driven recruitment of pDCs from the blood could be important in the regulation of arthritis pathology [116]. Sjogren's syndrome (SS), a prototypic systemic autoimmune disease associated with RA and SLE, is characterized by dry eyes and dry mouth due to the destruction of exocrine glands [117]. The abnormal production of extra anti-nulear autoantibodies in the blood and the great number of pDCs in the salivary glands [118] suggest that TLR7 and TLR9 self-recognition in pDCs might also contribute much to the overall inflammatory responses in SS patients.

\subsection{Potential use of pDCs-targeted immunomodulation in autoimmune diseases}

The emerging data indicate a causal relationship between autoimmune diseases and aberrant type I IFNs production. Usually patients with autoimmune diseases have increased levels of type I IFNs in serum and/or in the peripheral lymphoid tissues and sites of inflammation, which correlates to both disease activity and severity. Recent studies demonstrate that the expression of type I IFN genes and IFN-induced genes represents the most striking molecular signatures of SLE peripheral blood cells $[119,120]$. The approaches aimed at reducing the IFN-a level [121,122] and deleting B cells by antibodies [123] in lupus patients are currently being investigated, and early evaluation of clinical trials is extremely promising. However, pDC, as the main producer of type I IFNs, should be the target for therapeutic manipulations of the immune system to elicit a powerful modulation to treat autoimmune diseases in combination with other therapies.

Using anti-BDCA-2 monoclonal antibodies (mAbs), the IFN-a production by PBMCs stimulated with serum from SLE patients was markedly reduced [124], which suggests the direct ligation of pDC-specific markers such as BDCA-2 [125] and ILT7 [126] (Figure 2) may be a therapeutic option for inhibiting the ongoing IFN-a production in patients with autoimmune diseases. Antibody cross-linking of NKp44 [127] or Siglec-H [128] (Figure 2), receptors that signal through the ITAM (immunoreceptor-based tyrosine activation motif) bearing adaptor DAP12, reduces type I IFNs production by pDCs activated by TLR7 and TLR9 agonists in vitro and in vivo. Both the IgE engagement with FceRI $\gamma$ [129] and the IgG engagement with Fc $\gamma$ RIIA [130] downregulate type I IFNs production by human pDCs, which implies the employment of ITAM-mediated signaling pathway to modulate the pDC function. As a matter of fact, pDCs use a powerful ITAM-mediated, BCR-like regulatory pathway to counteract the prominent TLR signaling pathway [131,132]. Similarly, signaling molecules downstream the TLRs, such as MyD88, TRAF6, IRAK-1, IRAK-4 and IRF-7 (Figure 2), also represent potential therapeutic targets.

Other possible therapeutic approaches include elimination of the immune complexes containing self DNA/RNA and autoantibodies. Several methods can be used to reduce the amount of such endogenous IFN-a inducers, such as DNase and RNase treatments in SLE patients. DNase I has been implicated in the pathophysiology of SLE since the 1950s, and administration of exogenous human recombinant DNase I (hrDNase I) has been tried in SLE patients [133]. However, no clear therapeutic effect was noted partly due to the remaining RNA-containing ICs. The upregulation of cell surface Fas expression by hrDNase I treatment, which induces increased susceptibility to Fas-mediated apoptosis and results in more auto-antigenic DNA/RNA, may also contribute to explaining the inefficacy of hrDNase I in SLE [134]. The action of antigenic ICs on pDCs is also prevented by the blockade of Fc $\gamma$ RIIA using specific antibodies (Figure 3) or by the inhibition of the TLRs function using TLR antagonists. Immunoregulatory sequence (IRS) 954, a bifunctional ODN with antagonist activity for both TLR7 and TLR9, inhibits the induction of IFN-a by 
human pDCs and reduces symptoms in murine lupus models [135,136], indicating that IRS could be a novel therapeutic approach for human autoimmune diseases.

\section{Conclusions and perspectives}

After generation from HSC within the bone marrow, pDCs are continuously released into the peripheral blood stream. These cells display plasma cell morphology, selectively express TLR7 and TLR9 in their endosomal compartments, and are specialized in rapidly secreting massive amounts of type I IFNs upon viral infection. Type I IFNs produced by pDCs not only have inhibitory effects on viral replication, but also contribute to the activation of NK cells, B cells, T cells and mDCs. At a later stage of viral infection, pDCs differentiate to a unique type of mature DCs, which directly regulate the function of T cells, thus contributing to linking the innate and adaptive immune system. The sustained activation of pDCs and excessive expression of type I IFNs from pDCs in response to TLR stimulation by sensing self nucleic acids also function in the pathogenesis of autoimmune diseases.

Although recent studies have greatly enhanced our understanding of the pDCs function in antiviral immunity and autoimmunity, several fascinating questions remain to be further investigated. What is the specific and detailed pathway for pDC development? Do the TLR7- and TLR9- dependent pathways cooperate with the non-TLR pathways involved in nucleic recognition such as RIG-I/MDA [137] and cytosolic DNA sensor DAI [138] in response to viral infection? A wide range of autoimmune and inflammatory diseases are linked with dysregulated pDC activation and aberrant IFN-a production triggered by self nucleic acids coupled with HMGB1, autoantibodies and LL37. However, are there any other host-derived factors that break innate tolerance to self nucleic acids? How can we harness pDC biology to develop safe and effective immunotherapy for viral infectious diseases and autoimmune diseases?

\section{References}

1. Banchereau J, Steinman RM. Dendritic cells and the control of immunity. Nature. 1998; 392:245252. [PubMed: 9521319]

2. Shortman K, Liu YJ. Mouse and human dendritic cell subtypes. Nat Rev Immunol. 2002; 2:151161. [PubMed: 11913066]

3. Siegal FP, Kadowaki N, Shodell M, et al. The nature of the principal type 1 interferon-producing cells in human blood. Science. 1999; 284:1835-1837. [PubMed: 10364556]

4. Liu Y-J. IPC: Professional type 1 interferon-producing cells and plasmacytoid dendritic cell precursors. Annual rev immunol. 2005; 23:275-306. [PubMed: 15771572]

5. Ronnblom L, Pascual V. The innate immune system in SLE: type I interferons and dendritic cells. Lupus. 2008; 17:394-399. [PubMed: 18490415]

6. Gilliet M, Cao W, Liu YJ. Plasmacytoid dendritic cells: Sensing nucleic acids in viral infection and autoimmune diseases. Nat Rev Immunol. 2008; 8:594-606. [PubMed: 18641647]

7. Finke D, Eloranta ML, Ronnblom L. Endogenous type I interferon inducers in autoimmune diseases. Autoimmunity. 2009; 42:349-352. [PubMed: 19811298]

8. Charles J, Chaperot L, Salameire D, et al. Plasmacytoid dendritic cells and dermatological disorders: focus on their role in autoimmunity and cancer. Eur J Dermatol. 2010; 20:16-23. [PubMed: 19850548]

9. Lennert K, Remmele W. Karyometric research on lymph node cells in man. I. Germinoblasts, lymphoblasts \& lymphocytes. Acta Haematol. 1958; 19:99-113. [PubMed: 13520253]

10. Feller AC, Lennert K, Stein H, et al. Immunohistology and aetiology of histiocytic necrotizing lymphadenitis. Report of three instructive cases. Histopathology. 1983; 7:825-839. [PubMed: 6229466]

11. Facchetti F, Vermi W, Mason D, et al. The plasmacytoid monocyte/interferon producing cells. Virchows Arch. 2003; 443:703-717. [PubMed: 14586652] 
12. Facchetti F, de Wolf-Peeters C, Mason DY, et al. Plasmacytoid T cells. Immunohistochemical evidence for their monocyte/macrophage origin. Am J Pathol. 1988; 133:15-21. [PubMed: 3052093]

13. Grouard G, Rissoan MC, Filgueira L, et al. The enigmatic plasmacytoid T cells develop into dendritic cells with interleukin (IL)-3 and CD40-ligand. J Exp Med. 1997; 185:1101-1111. [PubMed: 9091583]

14. Trinchieri G, Santoli D. Anti-viral activity induced by culturing lymphocytes with tumor-derived or virus-transformed cells. Enhancement of human natural killer cell activity by interferon and antagonistic inhibition of susceptibility of target cells to lysis. J Exp Med. 1978; 147:1314-1333. [PubMed: 650156]

15. Perussia B, Fanning V, Trinchieri G. A leukocyte subset bearing HLA-DR antigens is responsible for in vitro alpha interferon production in response to viruses. Nat Immun Cell Growth Regul. 1985; 4:120-137. [PubMed: 2995798]

16. Abb J, Abb H, Deinhardt F. Phenotype of human alpha-interferon producing leucocytes identified by monoclonal antibodies. Clin Exp Immunol. 1983; 52:179-184. [PubMed: 6574829]

17. Ronnblom L, Ramstedt U, Alm GV. Properties of human natural interferon-producing cells stimulated by tumor cell lines. Eur J Immunol. 1983; 13:471-476. [PubMed: 6574913]

18. Dzionek A, Fuchs A, Schmidt P, et al. BDCA-2, BDCA-3, and BDCA-4: three markers for distinct subsets of dendritic cells in human peripheral blood. J Immunol. 2000; 165:6037-6046. [PubMed: 11086035]

19. D'Amico A, Wu L. The early progenitors of mouse dendritic cells and plasmacytoid predendritic cells are within the bone marrow hemopoietic precursors expressing Flt3. J Exp Med. 2003; 198:293-303. [PubMed: 12874262]

20. Shigematsu H, Reizis B, Iwasaki H, et al. Plasmacytoid dendritic cells activate lymphoid-specific genetic programs irrespective of their cellular origin. Immunity. 2004; 21:43-53. [PubMed: 15345219]

21. Wang YH, Liu YJ. Mysterious origin of plasmacytoid dendritic cell precursors. Immunity. 2004; 21:1-2. [PubMed: 15345213]

22. Blom B, Ho S, Antonenko S, et al. Generation of interferon alpha-producing predendritic cell (PreDC)2 from human CD34(+) hematopoietic stem cells. J Exp Med. 2000; 192:1785-1796. [PubMed: 11120775]

23. Brawand P, Fitzpatrick DR, Greenfield BW, et al. Murine plasmacytoid pre-dendritic cells generated from Flt3 ligand-supplemented bone marrow cultures are immature APCs. J Immunol. 2002; 169:6711-6719. [PubMed: 12471102]

24. Chen W, Antonenko S, Sederstrom JM, et al. Thrombopoietin cooperates with FLT3-ligand in the generation of plasmacytoid dendritic cell precursors from human hematopoietic progenitors. Blood. 2004; 103:2547-2553. [PubMed: 14670916]

25. Gilliet M, Boonstra A, Paturel C, et al. The development of murine plasmacytoid dendritic cell precursors is differentially regulated by FLT3-ligand and granulocyte/macrophage colonystimulating factor. J Exp Med. 2002; 195:953-958. [PubMed: 11927638]

26. Schotte R, Nagasawa M, Weijer K, et al. The ETS transcription factor Spi-B is required for human plasmacytoid dendritic cell development. J Exp Med. 2004; 200:1503-1509. [PubMed: 15583020]

27. Esashi E, Liu YJ. E-box protein E2-2 is a crucial regulator of plasmacytoid DC development. Eur J Immunol. 2008; 38:2386-2388. [PubMed: 18792016]

28. Nagasawa M, Schmidlin H, Hazekamp MG, et al. Development of human plasmacytoid dendritic cells depends on the combined action of the basic helix-loop-helix factor E2-2 and the Ets factor Spi-B. Eur J Immunol. 2008; 38:2389-2400. [PubMed: 18792017]

29. Pulendran B, Banchereau J, Burkeholder S, et al. Flt3-ligand and granulocyte colony-stimulating factor mobilize distinct human dendritic cell subsets in vivo. J Immunol. 2000; 165:566-572. [PubMed: 10861097]

30. Arpinati M, Green CL, Heimfeld S, et al. Granulocyte-colony stimulating factor mobilizes T helper 2-inducing dendritic cells. Blood. 2000; 95:2484-2490. [PubMed: 10753825] 
31. Penna G, Vulcano M, Sozzani S, et al. Differential migration behavior and chemokine production by myeloid and plasmacytoid dendritic cells. Hum Immunol. 2002; 63:1164-1171. [PubMed: 12480260]

32. Yoneyama H, Matsuno K, Zhang Y, et al. Evidence for recruitment of plasmacytoid dendritic cell precursors to inflamed lymph nodes through high endothelial venules. Int Immunol. 2004; 16:915928. [PubMed: 15159375]

33. O'Keeffe M, Hochrein H, Vremec D, et al. Mouse plasmacytoid cells: long-lived cells, heterogeneous in surface phenotype and function, that differentiate into CD8(+) dendritic cells only after microbial stimulus. J Exp Med. 2002; 196:1307-1319. [PubMed: 12438422]

34. Ito T, Kanzler H, Duramad O, et al. Specialization, kinetics, and repertoire of type 1 interferon responses by human plasmacytoid predendritic cells. Blood. 2006; 107:2423-2431. [PubMed: 16293610]

35. Asselin-Paturel C, Boonstra A, Dalod M, et al. Mouse type I IFN-producing cells are immature APCs with plasmacytoid morphology. Nat Immunol. 2001; 2:1144-1150. [PubMed: 11713464]

36. Dalod M, Salazar-Mather TP, Malmgaard L, et al. Interferon alpha/beta and interleukin 12 responses to viral infections: pathways regulating dendritic cell cytokine expression in vivo. J Exp Med. 2002; 195:517-528. [PubMed: 11854364]

37. Barchet W, Cella M, Odermatt B, et al. Virus-induced interferon alpha production by a dendritic cell subset in the absence of feedback signaling in vivo. J Exp Med. 2002; 195:507-516. [PubMed: 11854363]

38. Aderem A, Ulevitch RJ. Toll-like receptors in the induction of the innate immune response. Nature. 2000; 406:782-787. [PubMed: 10963608]

39. Janeway CA Jr, Medzhitov R. Innate immune recognition. Annu Rev Immunol. 2002; 20:197-216. [PubMed: 11861602]

40. Takeda K, Kaisho T, Akira S. Toll-like receptors. Annu Rev Immunol. 2003; 21:335-376. [PubMed: 12524386]

41. Kadowaki N, Ho S, Antonenko S, et al. Subsets of human dendritic cell precursors express different toll-like receptors and respond to different microbial antigens. J Exp Med. 2001; 194:863-869. [PubMed: 11561001]

42. Jarrossay D, Napolitani G, Colonna M, et al. Specialization and complementarity in microbial molecule recognition by human myeloid and plasmacytoid dendritic cells. Eur J Immunol. 2001; 31:3388-3393. [PubMed: 11745357]

43. Diebold SS, Kaisho T, Hemmi H, et al. Innate antiviral responses by means of TLR7-mediated recognition of single-stranded RNA. Science. 2004; 303:1529-1531. [PubMed: 14976261]

44. Heil F, Hemmi H, Hochrein H, et al. Species-specific recognition of single-stranded RNA via tolllike receptor 7 and 8. Science. 2004; 303:1526-1529. [PubMed: 14976262]

45. Lund JM, Alexopoulou L, Sato A, et al. Recognition of single-stranded RNA viruses by Toll-like receptor 7. Proc Natl Acad Sci USA. 2004; 101:5598-5603. [PubMed: 15034168]

46. Tabeta K, Georgel P, Janssen E, et al. Toll-like receptors 9 and 3 as essential components of innate immune defense against mouse cytomegalovirus infection. Proc Natl Acad Sci USA. 2004; 101:3516-3521. [PubMed: 14993594]

47. Krug A, French AR, Barchet W, et al. TLR9-dependent recognition of MCMV by IPC and DC generates coordinated cytokine responses that activate antiviral NK cell function. Immunity. 2004; 21:107-119. [PubMed: 15345224]

48. Lund J, Sato A, Akira S, et al. Toll-like receptor 9-mediated recognition of Herpes simplex virus-2 by plasmacytoid dendritic cells. J Exp Med. 2003; 198:513-520. [PubMed: 12900525]

49. Kawai T, Sato S, Ishii KJ, et al. Interferon-alpha induction through Toll-like receptors involves a direct interaction of IRF7 with MyD88 and TRAF6. Nat Immunol. 2004; 5:1061-1068. [PubMed: 15361868]

50. Hacker H, Redecke V, Blagoev B, et al. Specificity in Toll-like receptor signalling through distinct effector functions of TRAF3 and TRAF6. Nature. 2006; 439:204-207. [PubMed: 16306937]

51. Gohda J, Matsumura T, Inoue J. Cutting edge: TNFR-associated factor (TRAF) 6 is essential for MyD88-dependent pathway but not toll/IL-1 receptor domain-containing adaptor-inducing IFN- 
beta (TRIF)-dependent pathway in TLR signaling. J Immunol. 2004; 173:2913-2917. [PubMed: 15322147]

52. Kim TW, Staschke K, Bulek K, et al. A critical role for IRAK4 kinase activity in Toll-like receptor-mediated innate immunity. J Exp Med. 2007; 204:1025-1036. [PubMed: 17470642]

53. Yang K, Puel A, Zhang S, et al. Human TLR-7-, -8-, and -9-mediated induction of IFN-alpha/beta and -lambda Is IRAK-4 dependent and redundant for protective immunity to viruses. Immunity. 2005; 23:465-478. [PubMed: 16286015]

54. Suzuki N, Suzuki S, Yeh WC. IRAK-4 as the central TIR signaling mediator in innate immunity. Trends Immunol. 2002; 23:503-506. [PubMed: 12297423]

55. Doyle SL, Jefferies CA, Feighery C, et al. Signaling by Toll-like receptors 8 and 9 requires Bruton's tyrosine kinase. J Biol Chem. 2007; 282:36953-36960. [PubMed: 17932028]

56. Coccia EM, Severa M, Giacomini E, et al. Viral infection and Toll-like receptor agonists induce a differential expression of type I and lambda interferons in human plasmacytoid and monocytederived dendritic cells. Eur J Immunol. 2004; 34:796-805. [PubMed: 14991609]

57. Izaguirre A, Barnes BJ, Amrute S, et al. Comparative analysis of IRF and IFN-alpha expression in human plasmacytoid and monocyte-derived dendritic cells. J Leukoc Biol. 2003; 74:1125-1138. [PubMed: 12960254]

58. Kerkmann M, Rothenfusser S, Hornung V, et al. Activation with CpG-A and CpG-B oligonucleotides reveals two distinct regulatory pathways of type I IFN synthesis in human plasmacytoid dendritic cells. J Immunol. 2003; 170:4465-4474. [PubMed: 12707322]

59. Takaoka A, Yanai H, Kondo S, et al. Integral role of IRF-5 in the gene induction programme activated by Toll-like receptors. Nature. 2005; 434:243-249. [PubMed: 15665823]

60. Yanai H, Chen HM, Inuzuka T, et al. Role of IFN regulatory factor 5 transcription factor in antiviral immunity and tumor suppression. Proc Natl Acad Sci USA. 2007; 104:3402-3407. [PubMed: 17360658]

61. Yasuda K, Richez C, Maciaszek JW, et al. Murine dendritic cell type I IFN production induced by human IgG-RNA immune complexes is IFN regulatory factor (IRF) 5 and IRF7 dependent and is required for IL-6 production. J Immunol. 2007; 178:6876-6885. [PubMed: 17513736]

62. Tsujimura H, Tamura T, Ozato K. Cutting edge: IFN consensus sequence binding protein/IFN regulatory factor 8 drives the development of type I IFN-producing plasmacytoid dendritic cells. J Immunol. 2003; 170:1131-1135. [PubMed: 12538667]

63. Brinkmann MM, Spooner E, Hoebe K, et al. The interaction between the ER membrane protein UNC93B and TLR3, 7, and 9 is crucial for TLR signaling. J Cell Biol. 2007; 177:265-275. [PubMed: 17452530]

64. Yang Y, Liu B, Dai J, et al. Heat shock protein gp96 is a master chaperone for toll-like receptors and is important in the innate function of macrophages. Immunity. 2007; 26:215-226. [PubMed: 17275357]

65. Ito T, Amakawa R, Inaba M, et al. Differential regulation of human blood dendritic cell subsets by IFNs. J Immunol. 2001; 166:2961-2969. [PubMed: 11207245]

66. Fonteneau JF, Larsson M, Beignon AS, et al. Human immunodeficiency virus type 1 activates plasmacytoid dendritic cells and concomitantly induces the bystander maturation of myeloid dendritic cells. J Virol. 2004; 78:5223-5232. [PubMed: 15113904]

67. Jego G, Palucka AK, Blanck JP, et al. Plasmacytoid dendritic cells induce plasma cell differentiation through type I interferon and interleukin 6. Immunity. 2003; 19:225-234. [PubMed: 12932356]

68. Bandyopadhyay S, Perussia B, Trinchieri G, et al. Requirement for HLA-DR ${ }^{+}$accessory cells in natural killing of cytomegalovirus-infected fibroblasts. J Exp Med. 1986; 164:180-195. [PubMed: 3014033]

69. Oh SH, Bandyopadhyay S, Miller DS, et al. Cooperation between CD16(Leu-11b) ${ }^{+}$NK cells and HLA-DR ${ }^{+}$cells in natural killing of herpesvirus-infected fibroblasts. J Immunol. 1987; 139:2799_ 2802. [PubMed: 2821120]

70. Hanabuchi S, Watanabe N, Wang YH, et al. Human plasmacytoid predendritic cells activate NK cells through glucocorticoid-induced tumor necrosis factor receptor-ligand (GITRL). Blood. 2006; 107:3617-3623. [PubMed: 16397134] 
71. Le Bon A, Etchart N, Rossmann C, et al. Cross-priming of $\mathrm{CD}^{+} \mathrm{T}$ cells stimulated by virusinduced type I interferon. Nat Immunol. 2003; 4:1009-1015. [PubMed: 14502286]

72. Kolumam GA, Thomas S, Thompson LJ, et al. Type I interferons act directly on CD8 T cells to allow clonal expansion and memory formation in response to viral infection. J Exp Med. 2005; 202:637-650. [PubMed: 16129706]

73. Hibbert L, Pflanz S, De Waal Malefyt R, et al. IL-27 and IFN-alpha signal via Stat 1 and Stat3 and induce T-Bet and IL-12Rbeta2 in naive T cells. J Interferon Cytokine Res. 2003; 23:513-522. [PubMed: 14565860]

74. Kadowaki N, Antonenko S, Lau JY, et al. Natural interferon alpha/beta-producing cells link innate and adaptive immunity. J Exp Med. 2000; 192:219-226. [PubMed: 10899908]

75. Rissoan MC, Soumelis V, Kadowaki N, et al. Reciprocal control of T helper cell and dendritic cell differentiation. Science. 1999; 283:1183-1186. [PubMed: 10024247]

76. Ito T, Yang M, Wang YH, et al. Plasmacytoid dendritic cells prime IL-10-producing T regulatory cells by inducible costimulator ligand. J Exp Med. 2007; 204:105-115. [PubMed: 17200410]

77. Penna G, Sozzani S, Adorini L. Cutting edge: selective usage of chemokine receptors by plasmacytoid dendritic cells. J Immunol. 2001; 167:1862-1866. [PubMed: 11489962]

78. Feldman S, Stein D, Amrute S, et al. Decreased interferon-alpha production in HIV-infected patients correlates with numerical and functional deficiencies in circulating type 2 dendritic cell precursors. Clin Immunol. 2001; 101:201-210. [PubMed: 11683579]

79. Pacanowski J, Kahi S, Baillet M, et al. Reduced blood CD123+ (lymphoid) and CD11c ${ }^{+}$(myeloid) dendritic cell numbers in primary HIV-1 infection. Blood. 2001; 98:3016-3021. [PubMed: 11698285]

80. Soumelis V, Scott I, Gheyas F, et al. Depletion of circulating natural type 1 interferon-producing cells in HIV-infected AIDS patients. Blood. 2001; 98:906-912. [PubMed: 11493432]

81. Chehimi J, Campbell DE, Azzoni L, et al. Persistent decreases in blood plasmacytoid dendritic cell number and function despite effective highly active antiretroviral therapy and increased blood myeloid dendritic cells in HIV-infected individuals. J Immunol. 2002; 168:4796-4801. [PubMed: 11971031]

82. Hardy AW, Graham DR, Shearer GM, et al. HIV turns plasmacytoid dendritic cells (pDC) into TRAIL-expressing killer pDC and down-regulates HIV coreceptors by Toll-like receptor 7induced IFN-alpha. Proc Natl Acad Sci USA. 2007; 104:17453-17458. [PubMed: 17956986]

83. Mandl JN, Barry AP, Vanderford TH, et al. Divergent TLR7 and TLR9 signaling and type I interferon production distinguish pathogenic and nonpathogenic AIDS virus infections. Nat Med. 2008; 14:1077-1087. [PubMed: 18806803]

84. Jacquelin B, Mayau V, Targat B, et al. Nonpathogenic SIV infection of African green monkeys induces a strong but rapidly controlled type I IFN response. J Clin Invest. 2009; 119:3544-3555. [PubMed: 19959873]

85. Bosinger SE, Li Q, Gordon SN, et al. Global genomic analysis reveals rapid control of a robust innate response in SIV-infected sooty mangabeys. J Clin Invest. 2009; 119:3556-3572. [PubMed: 19959874]

86. O'Connell K, Siliciano RF. Immune alteration fends off AIDS. Nat Med. 2008; 14:1016-1018. [PubMed: 18841135]

87. Manches O, Bhardwaj N. Resolution of immune activation defines nonpathogenic SIV infection. J Clin Invest. 2009; 119:3512-3515. [PubMed: 19959871]

88. Duan XZ, Wang M, Li HW, et al. Decreased frequency and function of circulating plasmocytoid dendritic cells (pDC) in hepatitis B virus infected humans. J Clin Immunol. 2004; 24:637-646. [PubMed: 15622448]

89. van der Molen RG, Sprengers D, Binda RS, et al. Functional impairment of myeloid and plasmacytoid dendritic cells of patients with chronic hepatitis B. Hepatology. 2004; 40:738-746. [PubMed: 15349914]

90. Duan XZ, Zhuang H, Wang M, et al. Decreased numbers and impaired function of circulating dendritic cell subsets in patients with chronic hepatitis B infection (R2). J Gastroenterol Hepatol. 2005; 20:234-242. [PubMed: 15683426] 
91. Zhang Z, Zhang H, Chen D, et al. Response to interferon-alpha treatment correlates with recovery of blood plasmacytoid dendritic cells in children with chronic hepatitis B. J Hepatol. 2007; 47:751-759. [PubMed: 17920718]

92. Untergasser A, Zedler U, Langenkamp A, et al. Dendritic cells take up viral antigens but do not support the early steps of hepatitis B virus infection. Hepatology. 2006; 43:539-547. [PubMed: 16496321]

93. Chutinimitkul S, Bhattarakosol P, Srisuratanon S, et al. H5N1 influenza A virus and infected human plasma. Emerg Infect Dis. 2006; 12:1041-1043. [PubMed: 16752481]

94. Uiprasertkul M, Puthavathana P, Sangsiriwut K, et al. Influenza A H5N1 replication sites in humans. Emerg Infect Dis. 2005; 11:1036-1041. [PubMed: 16022777]

95. Sandbulte MR, Boon AC, Webby RJ, et al. Analysis of cytokine secretion from human plasmacytoid dendritic cells infected with $\mathrm{H} 5 \mathrm{~N} 1$ or low-pathogenicity influenza viruses. Virology. 2008; 381:22-28. [PubMed: 18801551]

96. Thitithanyanont A, Engering A, Ekchariyawat P, et al. High susceptibility of human dendritic cells to avian influenza H5N1 virus infection and protection by IFN-alpha and TLR ligands. J Immunol. 2007; 179:5220-5227. [PubMed: 17911607]

97. Osterlund P, Pirhonen J, Ikonen N, et al. Pandemic H1N1 2009 influenza a virus induces weak cytokine response in human macrophages and dendritic cells and is highly sensitive to antiviral actions of interferons. J Virol. 2010; 84:1414-1422. [PubMed: 19939920]

98. Yasuda K, Yu P, Kirschning CJ, et al. Endosomal translocation of vertebrate DNA activates dendritic cells via TLR9-dependent and -independent pathways. J Immunol. 2005; 174:6129_ 6136. [PubMed: 15879108]

99. Barton GM, Kagan JC, Medzhitov R. Intracellular localization of Toll-like receptor 9 prevents recognition of self DNA but facilitates access to viral DNA. Nat Immunol. 2005; 7:49-56. [PubMed: 16341217]

100. Stacey KJ, Young GR, Clark F, et al. The molecular basis for the lack of immunostimulatory activity of vertebrate DNA. J Immunol. 2003; 170:3614-3620. [PubMed: 12646625]

101. Kariko K, Buckstein M, Ni H, et al. Suppression of RNA recognition by Toll-like receptors: the impact of nucleoside modification and the evolutionary origin of RNA. Immunity. 2005; 23:165175. [PubMed: 16111635]

102. Barrat FJ, Meeker T, Gregorio J, et al. Nucleic acids of mammalian origin can act as endogenous ligands for Toll-like receptors and may promote systemic lupus erythematosus. J Exp Med. 2005; 202:1131-1139. [PubMed: 16230478]

103. Marshak-Rothstein A. Toll-like receptors in systemic autoimmune disease. Nat Rev Immunol. 2006; 6:823-835. [PubMed: 17063184]

104. Bengtsson AA, Sturfelt G, Truedsson L, et al. Activation of type I interferon system in systemic lupus erythematosus correlates with disease activity but not with antiretroviral antibodies. Lupus. 2000; 9:664-671. [PubMed: 11199920]

105. Ronnblom L, Alm GV. Systemic lupus erythematosus and the type I interferon system. Arthritis Res Ther. 2003; 5:68-75. [PubMed: 12718746]

106. Tian J, Avalos AM, Mao SY, et al. Toll-like receptor 9-dependent activation by DNA-containing immune complexes is mediated by HMGB1 and RAGE. Nat Immunol. 2007; 8:487-496.

[PubMed: 17417641]

107. Blanco P, Palucka AK, Gill M, et al. Induction of dendritic cell differentiation by IFN-alpha in systemic lupus erythematosus. Science. 2001; 294:1540-1543. [PubMed: 11711679]

108. Ittah M, Miceli-Richard C, Eric Gottenberg J, et al. B cell-activating factor of the tumor necrosis factor family (BAFF) is expressed under stimulation by interferon in salivary gland epithelial cells in primary Sjogren's syndrome. Arthritis Res Ther. 2006; 8:R51. [PubMed: 16507175]

109. Daridon C, Devauchelle V, Hutin P, et al. Aberrant expression of BAFF by B lymphocytes infiltrating the salivary glands of patients with primary Sjogren's syndrome. Arthritis Rheum. 2007; 56:1134-1144. [PubMed: 17393395]

110. Barrat FJ, Coffman RL. Development of TLR inhibitors for the treatment of autoimmune diseases. Immunol Rev. 2008; 223:271-283. [PubMed: 18613842] 
111. Lowes MA, Bowcock AM, Krueger JG. Pathogenesis and therapy of psoriasis. Nature. 2007; 445:866-873. [PubMed: 17314973]

112. Nestle FO, Conrad C, Tun-Kyi A, et al. Plasmacytoid predendritic cells initiate psoriasis through interferon-alpha production. J Exp Med. 2005; 202:135-143. [PubMed: 15998792]

113. Lande R, Gregorio J, Facchinetti V, et al. Plasmacytoid dendritic cells sense self-DNA coupled with antimicrobial peptide. Nature. 2007; 449:564-569. [PubMed: 17873860]

114. Sandgren S, Wittrup A, Cheng F, et al. The human antimicrobial peptide LL-37 transfers extracellular DNA plasmid to the nuclear compartment of mammalian cells via lipid rafts and proteoglycan-dependent endocytosis. J Biol Chem. 2004; 279:17951-17956. [PubMed: 14963039]

115. Ganguly D, Chamilos G, Lande R, et al. Self-RNA-antimicrobial peptide complexes activate human dendritic cells through TLR7 and TLR8. J Exp Med. 2009; 206:1983-1994. [PubMed: 19703986]

116. Lande R, Giacomini E, Serafini B, et al. Characterization and recruitment of plasmacytoid dendritic cells in synovial fluid and tissue of patients with chronic inflammatory arthritis. $\mathrm{J}$ Immunol. 2004; 173:2815-2824. [PubMed: 15295000]

117. Kruszka P, O’Brian RJ. Diagnosis and management of Sjogren syndrome. Am Fam Physician. 2009; 79:465-470. [PubMed: 19323359]

118. Gottenberg JE, Cagnard N, Lucchesi C, et al. Activation of IFN pathways and plasmacytoid dendritic cell recruitment in target organs of primary Sjogren's syndrome. Proc Natl Acad Sci USA. 2006; 103:2770-2775. [PubMed: 16477017]

119. Bennett L, Palucka AK, Arce E, et al. Interferon and granulopoiesis signatures in systemic lupus erythematosus blood. J Exp Med. 2003; 197:711-723. [PubMed: 12642603]

120. Baechler EC, Batliwalla FM, Karypis G, et al. Interferon-inducible gene expression signature in peripheral blood cells of patients with severe lupus. Proc Natl Acad Sci USA. 2003; 100:2610 2615. [PubMed: 12604793]

121. Wallace DJ, Petri M, Olsen N, et al. MEDI-545, an anti-interferon alpha monoclonal antibody, shows evidence of clinical activity in systemic lupus erythematosus. Arthritis Rheumatoid. 2007:S526-S527.

122. Zagury D, Le Buanec H, Mathian A, et al. IFNalpha kinoid vaccine- induced neutralizing antibodies prevent clinical manifestations in a lupus flare murine model. Proc Natl Acad Sci USA. 2009; 106:5294-5299. [PubMed: 19279210]

123. Eisenberg R, Albert D. B-cell targeted therapies in rheumatoid arthritis and systemic lupus erythematosus. Nat Clin Pract Rheumatol. 2006; 2:20-27. [PubMed: 16932648]

124. Blomberg S, Eloranta ML, Magnusson M, et al. Expression of the markers BDCA-2 and BDCA-4 and production of interferon-alpha by plasmacytoid dendritic cells in systemic lupus erythematosus. Arthritis Rheum. 2003; 48:2524-2532. [PubMed: 13130472]

125. Dzionek A, Sohma Y, Nagafune J, et al. BDCA-2, a novel plasmacytoid dendritic cell-specific type II C-type lectin, mediates antigen capture and is a potent inhibitor of interferon alpha/beta induction. J Exp Med. 2001; 194:1823-1834. [PubMed: 11748283]

126. Cao W, Rosen DB, Ito T, et al. Plasmacytoid dendritic cell-specific receptor ILT7-Fc epsilonRI gamma inhibits Toll-like receptor-induced interferon production. J Exp Med. 2006; 203:13991405. [PubMed: 16735691]

127. Fuchs A, Cella M, Kondo T, et al. Paradoxic inhibition of human natural interferon-producing cells by the activating receptor NKp44. Blood. 2005; 106:2076-2082. [PubMed: 15941912]

128. Blasius AL, Cella M, Maldonado J, et al. Siglec-H is an IPC-specific receptor that modulates type I IFN secretion through DAP12. Blood. 2006; 107:2474-2476. [PubMed: 16293595]

129. Schroeder JT, Bieneman AP, Xiao H, et al. TLR9- and FcepsilonRI-mediated responses oppose one another in plasmacytoid dendritic cells by down-regulating receptor expression. J Immunol. 2005; 175:5724-5731. [PubMed: 16237063]

130. Bave U, Magnusson M, Eloranta ML, et al. Fc gamma RIIa is expressed on natural IFN-alphaproducing cells (plasmacytoid dendritic cells) and is required for the IFN-alpha production induced by apoptotic cells combined with lupus IgG. J Immunol. 2003; 171:3296-3302. [PubMed: 12960360] 
131. Cao W, Zhang L, Rosen DB, et al. BDCA2/Fc epsilon RI gamma complex signals through a novel BCR-like pathway in human plasmacytoid dendritic cells. PLoS Biol. 2007; 5:e248. [PubMed: 17850179]

132. Rock J, Schneider E, Grun JR, et al. CD303 (BDCA-2) signals in plasmacytoid dendritic cells via a BCR-like signalosome involving Syk, Slp65 and PLCgamma2. Eur J Immunol. 2007; 37:35643575. [PubMed: 18022864]

133. Martinez Valle F, Balada E, Ordi-Ros J, et al. DNase 1 and systemic lupus erythematosus. Autoimmunity Reviews. 2008; 7:359-363. [PubMed: 18486922]

134. Tinazzi E, Puccetti A, Gerli R, et al. Serum DNase I, soluble Fas/FasL levels and cell surface Fas expression in patients with SLE: a possible explanation for the lack of efficacy of hrDNase I treatment. Int Immunol. 2009; 21:237-243. [PubMed: 19181929]

135. Barrat FJ, Meeker T, Chan JH, et al. Treatment of lupus-prone mice with a dual inhibitor of TLR7 and TLR9 leads to reduction of autoantibody production and amelioration of disease symptoms. Eur J Immunol. 2007; 37:3582-3586. [PubMed: 18034431]

136. Pawar RD, Ramanjaneyulu A, Kulkarni OP, et al. Inhibition of Toll-like receptor-7 (TLR-7) or TLR-7 plus TLR-9 attenuates glomerulonephritis and lung injury in experimental lupus. J Am Soc Nephrol. 2007; 18:1721-1731. [PubMed: 17460144]

137. Akira S, Uematsu S, Takeuchi O. Pathogen recognition and innate immunity. Cell. 2006; 124:783-801. [PubMed: 16497588]

138. Takaoka A, Wang Z, Choi MK, et al. DAI (DLM-1/ZBP1) is a cytosolic DNA sensor and an activator of innate immune response. Nature. 2007; 448:501-505. [PubMed: 17618271] 

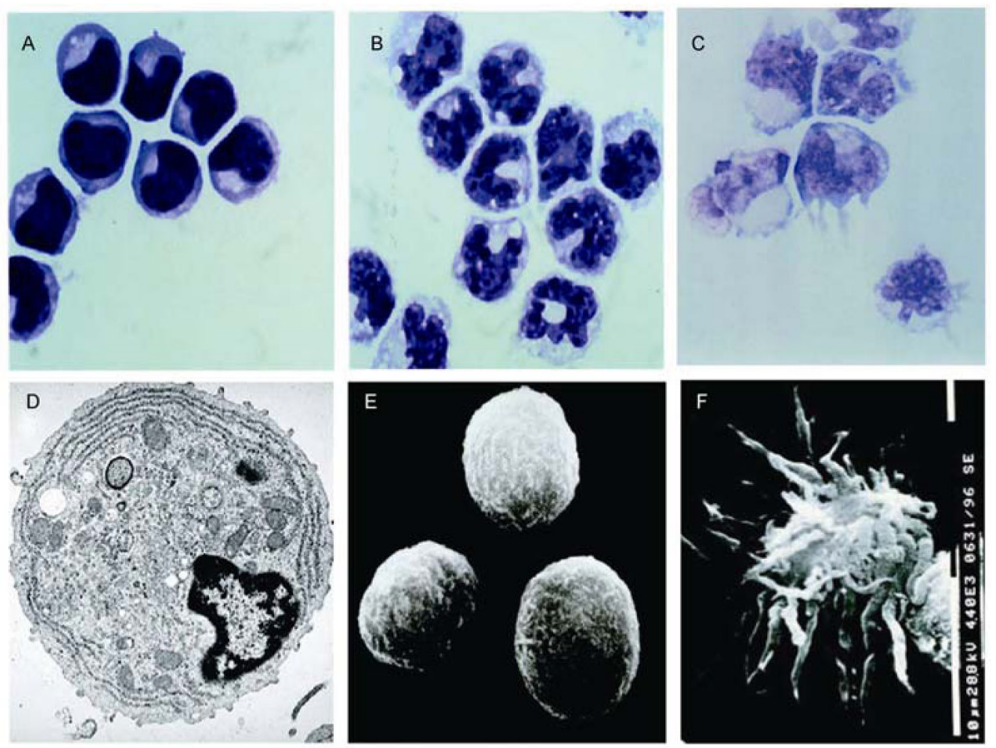

Figure 1.

Morphology of pDCs. A-C, Giemsa staining of pDCs (A), monocytes (B) and CD11 $\mathrm{c}^{+}$ mDCs $(C)$; D, transmission EM of pDCs; E, scanning EM of immature pDCs; F, scanning EM of mature pDCs activated by IL-3 and CD40L. Original magnifications, $1000 \times(A, B, C)$, $7000 \times(\mathrm{D})$ and $3000 \times(\mathrm{E}, \mathrm{F})$. 


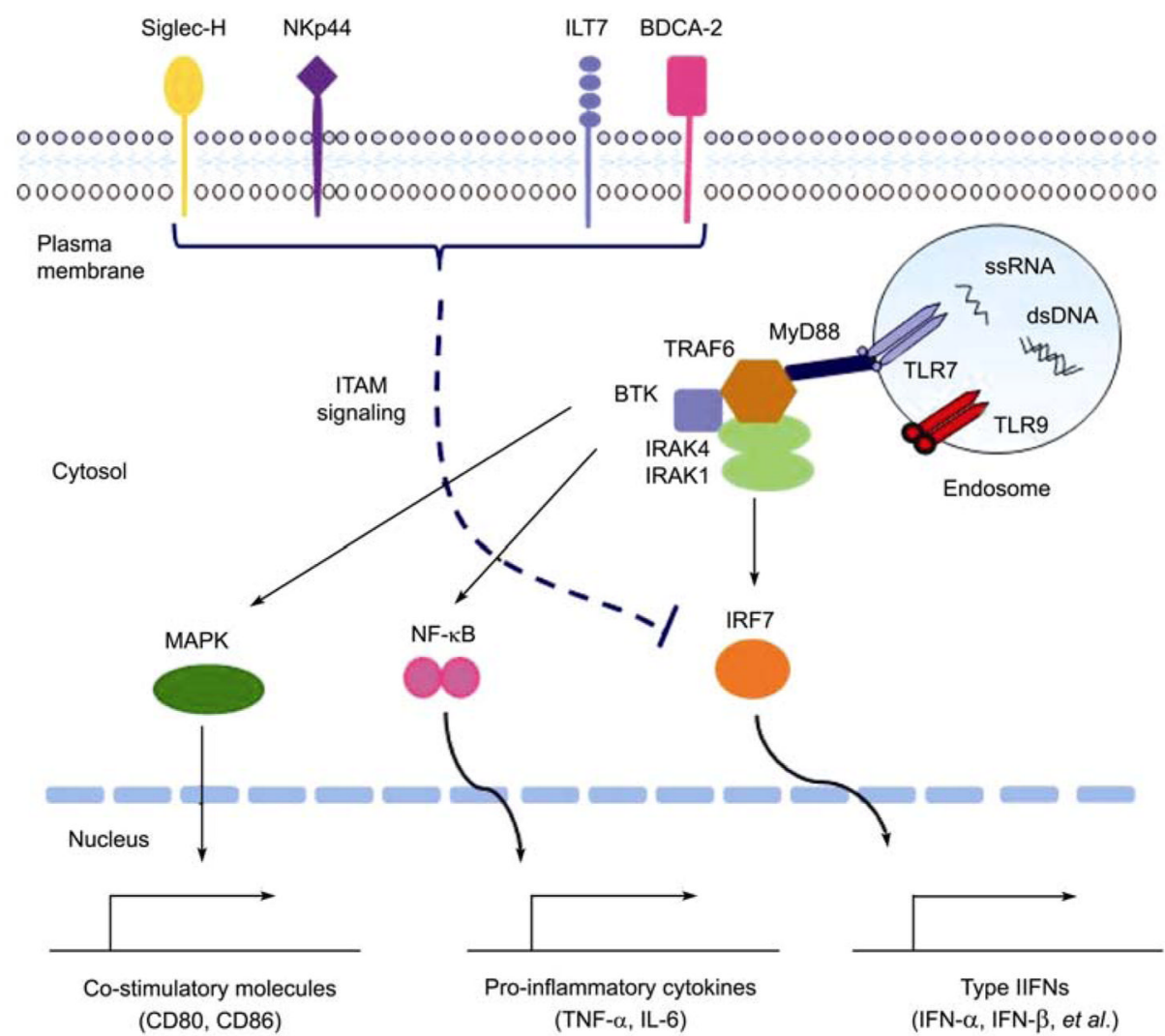

Figure 2.

The activation pathway of pDCs responding to viral nucleic acids and negative regulation of the pDC function by surface receptors. When exposed to viruses or nucleic acids, TLR7 and TLR9 translocate to the endosome to get engaged with ssRNA or dsDNA, leading to the conformational changes in the TLRs. Then a multi-protein signaling complex is formed, including MyD88, BTK, TRAF6, IRAK1, and IRAK4, and this complex activates MAPKs and transcriptional factors, such as NF- $\kappa \mathrm{B}$, and IRF7. Following the activation, the transcription factors translocate into nuclei and initiate the transcription of type I IFNs, proinflammatory cytokines (such as IL-6 and TNF-a), and co-stimulatory molecules (such as CD80, CD86). Meanwhile, pDCs express some surface regulatory receptors, such as BDCA-2, ILT7, NKp44, and Siglec-H, to inhibit type I IFNs production through the ITAM signaling pathway. 


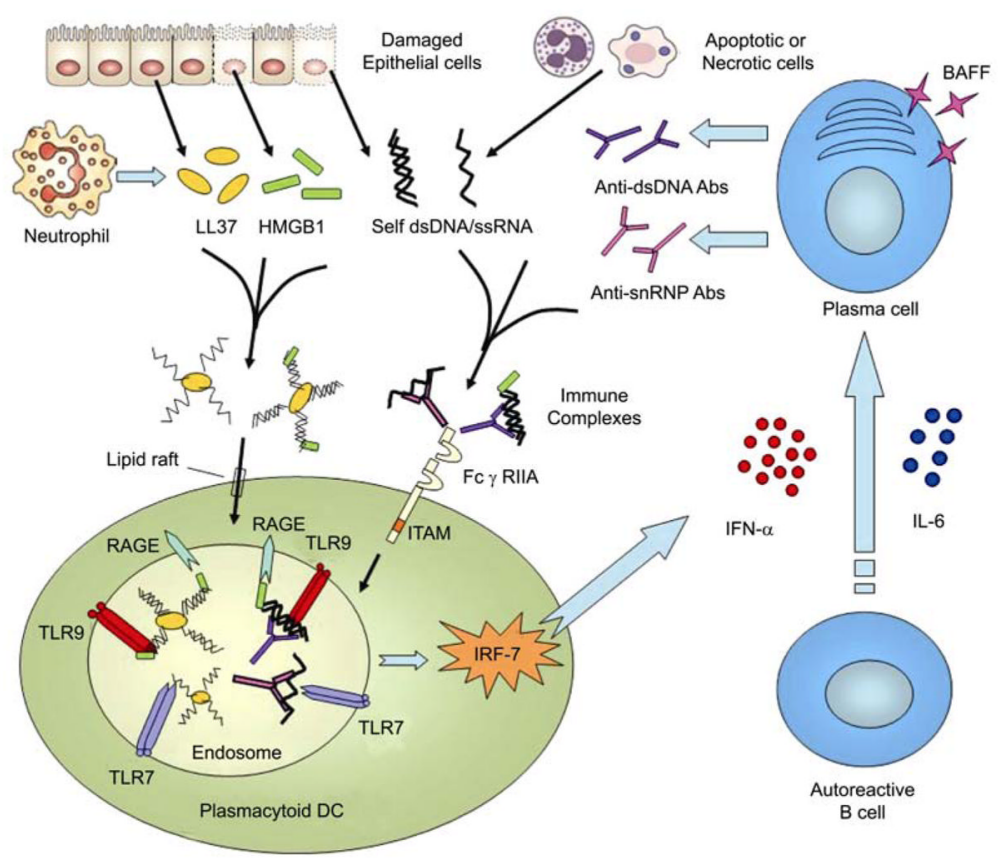

Figure 3.

A model for recognition of self-DNA and self-RNA by pDCs. LL37 binds self-DNA and self-RNA fragments released by dying cells to form aggregated and condensed structures that are protected from extracellular nuclease degradation. HMGB1, derived from the dying cells, binds aggregated self-DNA-LL37 complexes or dsDNA-autoantibodies immune complexes and promotes their association with TLR9 through interacting with RAGE. In SLE, the aberrantly expressed IFN-a from pDCs, together with IL-6, stimulates the differentiation of autoreactive B cells into plasma cells and expression of B cell survival factor BAFF. This could contribute to amplification of the pathogenic loop in which pDCs produce more type I IFNs and subsequently promote the differentiation of autoreactive plasma cells that would further secret autoantibodies to form immune complexes to activate pDCs. 